\title{
Efficient and Reproducible Synthesis of an Fmoc-protected Tn Antigen
}

Michael R. Reynolds†, Sabrina M. Piazza†, Jonathan Chiaramonte, Fabiola A. Chapa-Villarreal, John F. Trant*

Department of Chemistry and Biochemistry, University of Windsor,

401 Sunset Avenue, Windsor, ON, N9B 3P4, Canada

† These authors contributed equally to this work and the order is due to the arbitrary vagaries arising from the combination of the Latin alphabet and family name alone. Both authors, and those citing this work, may invert the order of the first two authors for any and all professional purposes. The preprint of this article inverts the names with the same statement to emphasize this point.

Dedication: In memory of Jonathan Chiaramonte, friend and colleague.

\begin{abstract}
The total synthesis of the Thomsen-nouveau (Tn) antigen, a tumour-associated O-linked mucin glycopeptide, was achieved through a concise route. The key glycosylation step proved challenging to reproduce from the literature precedents and was most reliably accomplished using a palladium-catalyzed coupling between the glycosyl donor and Fmoc-functionalized serine acceptor to form the target in moderate yields. This is, to the best of our knowledge, the shortest synthesis reported from galactose for preparing this essential building block for large-scale solid phase peptide synthesis.
\end{abstract}

Keywords: Glycoconjugate, Glycosylation, Tumour-Associated Carbohydrate Antigen, Palladium Lewis Acid, Bioorganic Synthesis, Immunotherapy 


\section{Introduction}

Cancer is a leading cause of death globally. Despite constant advances in treatment, the percentage of cancer-related deaths is expected to increase in the developed world as other fatal conditions are continuously becoming better controlled. ${ }^{1}$ Although there is ever accelerating innovation in the treatment of cancer, progress remains agonizingly slow due to the enormous diversity of mutations responsible for causing cancer. ${ }^{2}$ The current primary triad of surgery and/or radiation/chemotherapy both in tandem or individually can be highly effective; ${ }^{3}$ but success is greatly dependent on a series of variables including (but not limited to): the location of the disease, metastasis status, types of mutations present, and stage at detection. Available tools are particularly lacking for late stage cancers, with only a few targeted therapies recently becoming available, ${ }^{4}$ such as hormone therapy for breast, ${ }^{5}$ and prostate $^{6}$ cancer have provided improved survivability; however, in many cases they still often only lead to short term improvement, with disease recurrence emerging as the cancer mutates to resist the treatment. We need additional therapeutic modalities to complement this therapeutic triad. Cancer vaccines are a promising avenue as they could re-engage the body's immune system to the battle. For many purposes, cancer can be defined as uncontrolled cell growth that has evaded the immune system, and will eventually progress to the death of the host ${ }^{1}$ : the vast majority of precancerous clusters are hypothesized to be cleared by the immune system long before they can develop into a tumor. ${ }^{7}$ When looking to activate the immune system, vaccines are particularly attractive ${ }^{8}$ however, they require the identification of biomarkers correlated with cancer. Unfortunately, many oncotargets are simply upregulated in cancer. As they are also present on healthy cells, they are inappropriate vaccine targets as stimulation would initiate a systemic and very dangerous immune response. Tumor-Associated Carbohydrate Antigens (TACAs) are different as they are not found on healthy adult tissue, yet 
are found on over $90 \%$ of biopsied carcinomas (i.e. breast, ovarian, colon, lung, and prostate cancers). ${ }^{9}$ This discrepancy is because they form the core of many surface carbohydrates, but are always further elaborated. In cancer, the misregulation of glycosyl transferases ensures that they remain naked. Their precise role in oncogenesis is unclear, but overexpression is generally correlated with a poor prognosis. ${ }^{1,10}$ These carbohydrate antigens have, when incorporated into glycopeptides or other immunogenic scaffolds, formed the basis of the development of anti-tumor immunotherapies through the induction of a specific immune response against cancer cells. ${ }^{11}$ However, ready access to these materials is missing from the literature, and a simple scalable synthesis is required. As part of an extensive carbohydrate vaccine effort, we needed a route to produce the simplest TACA, the peracetylated Tn antigen (1), 2-deoxy-2- $N$-acetylamino-Dgalactose (GalNac)- $O$-serine with an Fmoc present for solid phase peptide synthesis (SPPS) on multigram, and up to $100 \mathrm{~g}$ scale. Although this molecule has been prepared repeatedly in the past, ${ }^{12}$ we found many of the simple published routes were inconsistent batch-to-batch and couldn't always be reproduced if the chemist doing the reactions changed. ${ }^{13}$ Furthermore, published routes often required complex protecting group strategies that increased the step and purification count, decreasing yield (Figure 1). We wish to report the route we are using for this scale-up and that can be readily executed by a junior undergraduate student. 

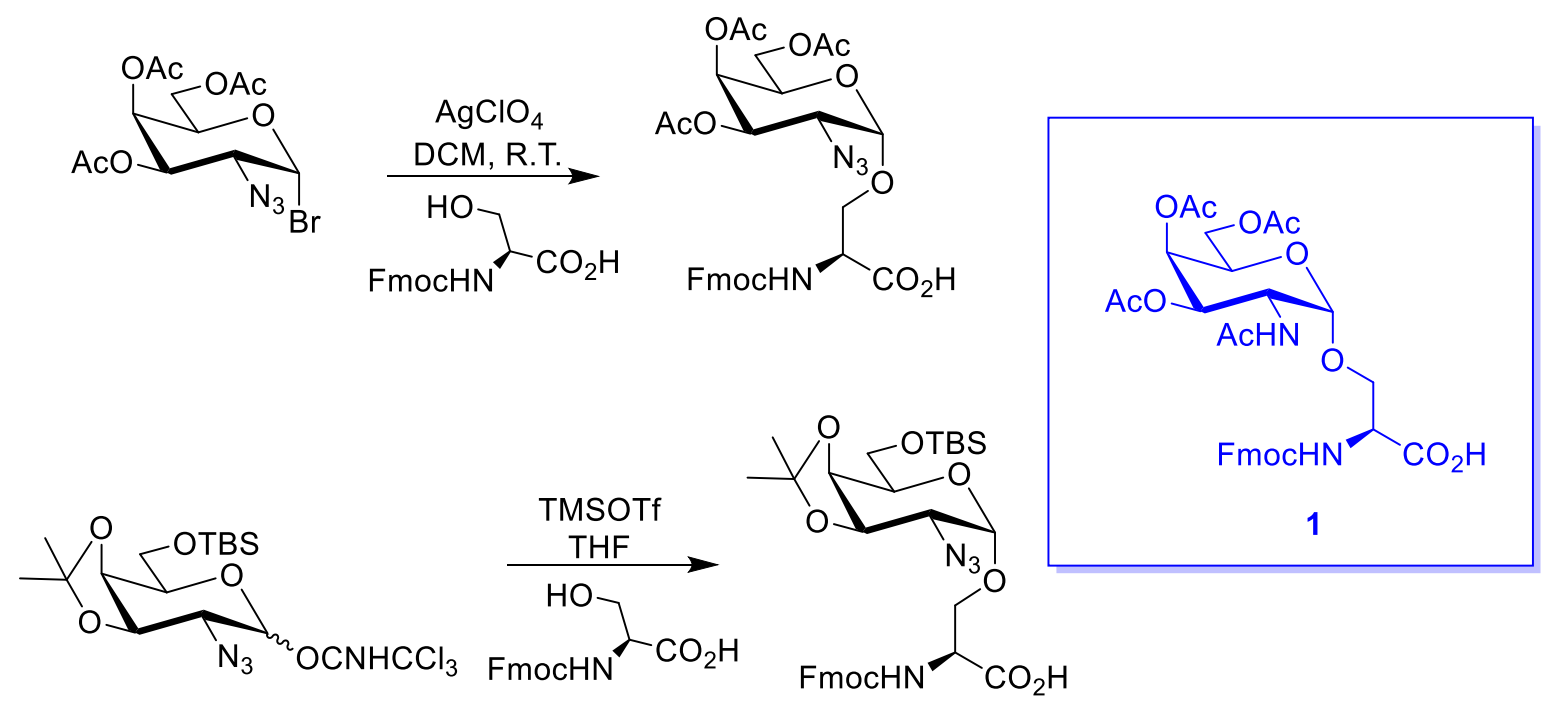

Figure 1: A) Danishefsky's first generation synthesis towards the Fmoc-protected peracetylated Tn antigen (1); $\left.{ }^{13 a} \mathrm{~B}\right)$ Danishefsky's second generation synthesis of the Fmoc-protected Tn antigen. ${ }^{13 a}$

\section{Results and Discussion:}

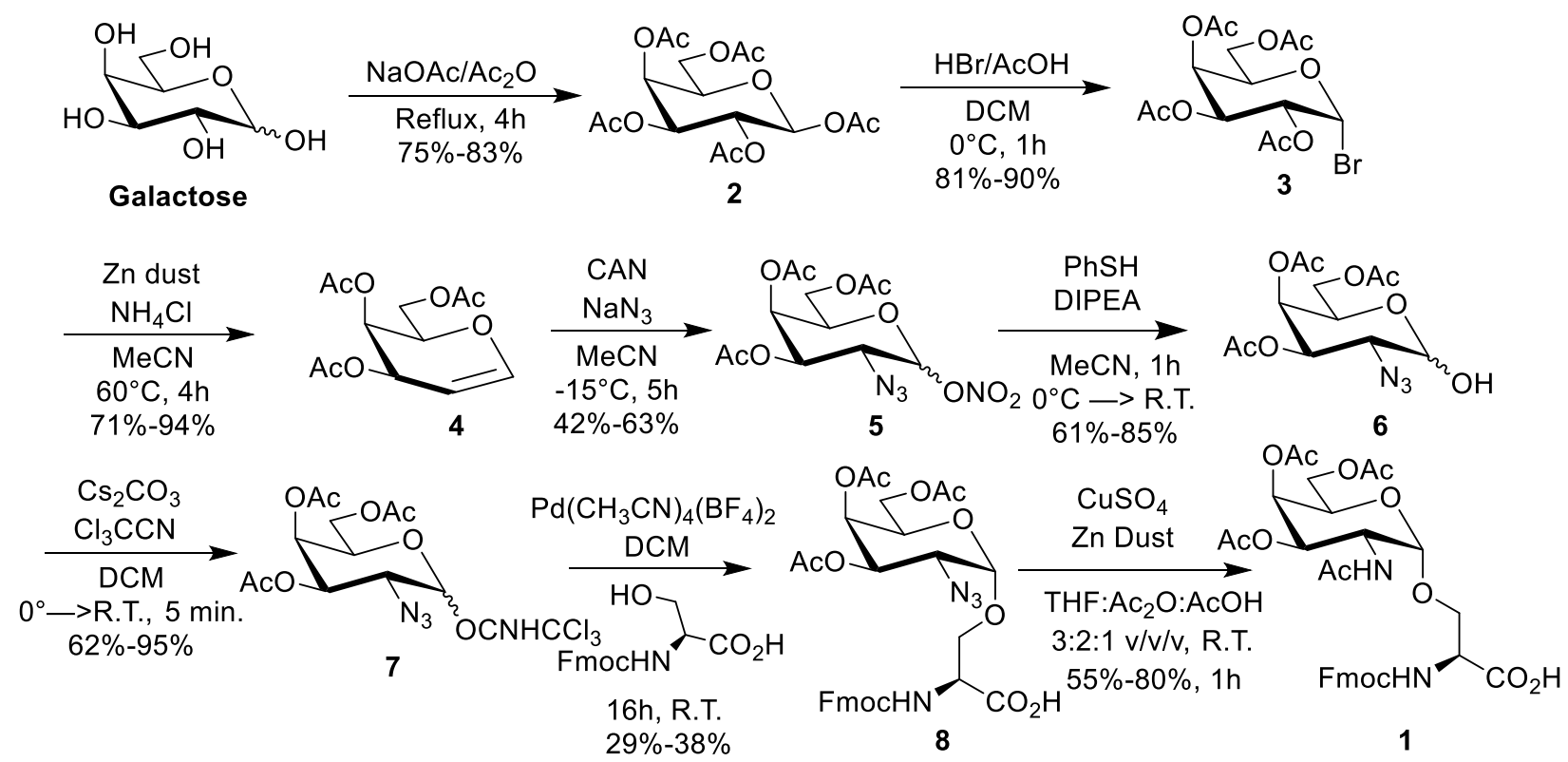

Figure 2: Synthesis of the Tn Antigen, protected for solid-phase peptide synthesis. Yields are reported as ranges of yields from multiple trials and multiple operators. 
Our synthetic approach begins with a series of well-precedented steps. A medium scale peracetylation of D-galactose (100 g scale) provided a $78 \%$ yield of the $\beta$ anomer after recrystallization from methanol. Subsequent bromination in strong acid yielded the galactosyl bromide 3 in good yield after precipitation. Treatment of the unstable bromosugar ${ }^{14}$ with zinc metal in acetonitrile at reflux, provides bench stable galactal $\mathbf{4}$ in high yield. Although other approaches were explored, ${ }^{13 a}$ this route proved to be the most reliable access to this material, with no chromatography needed until the purification of galactal.

To introduce the C2-amine, we found that Lemieux's ceric ammonium nitrate (CAN)mediated azidonitration was highly effective and robust providing crude $\mathbf{5},{ }^{15}$ with the anomeric nitrate able to be readily hydrolysed to provide reducing sugar $\mathbf{6}$. This transformation, although effective, does result in the formation of inseparable byproducts and although $\mathbf{6}$ is crystallizable, this is very slow and inefficient, and so chromatography must be performed. This hemiacetal was converted to a large number of different activating groups (see references above), but yields for introducing the activating group were highly variable and the subsequent glycosylations inevitably inconsistent. Schmidt's trichloroacetamidates (TCA) were found to be the most promising. ${ }^{16}$ General protocols call for the use of potassium carbonate; however, we found that the more soluble cesium carbonate reduced reaction times from several hours to mere minutes with a concomitant reduction in product decomposition, leading to higher yields. This intermediate should be used immediately upon isolation to minimize background hydrolysis.

TACAs are generally made to be incorporated into peptides using standard solid phase synthesis methods. This requires that the product have an Fmoc-protected amino group and a free acid. Fmoc amino acids are notoriously challenging to couple and manipulate compared to Bocprotected analogues, and a common approach involves making the glycoconjugate, deprotecting 
the Boc group, and installing the Fmoc. This is inefficient especially as the price difference between Boc and Fmoc amino acids continues to close, and as Fmoc-installation is non-trivial. Similarly, we wanted to avoid conditions that required the carboxylate group on the amino acid to be protected; minimizing steps on the more complex molecule was a central requirement of our approach, both to minimize linear step count and to minimize the risks inherent to any transformation on valuable material. Consequently we only focused on published methods that used Fmoc-Ser(OH)-OH as the partner. All these routes use one of only a handful of Lewis acids as promoter. These proved unsuccessful (Table 1). The best result, 3\%, was obtained with TMSOTf over a 24 hour reaction time with only moderate conversion. Product decomposition was observed if the reaction was left sealed for longer time which lowered the isolated yield and also complicated isolation due to the higher impurity profile. Generally, the reactions were sluggish with slow consumption of starting material, and then product decomposition under the reaction conditions. All Lewis acids were freshly distilled under Schlenk technique, all solvents were obtained using air-free techniques directly from ketal stills, or a solvent purification system. All transfers were made using air free techniques and all reactions were run in the presence of $4 \AA$ molecular sieves. Advantageous water was not a serious challenge explaining the limited conversions.

Table 1. Attempted Conditions for the conversion of TCA 7 to glycoconjugate 8.

\begin{tabular}{|l|c|c|c|c|c|}
\hline Promotor & Promotor & Solvent & & \\
& Equivalents & & Temperature & Duration & Yield \\
\hline $\mathrm{BF}_{3} \mathrm{OEt}_{2}$ & $0.4 / \mathrm{h}(\mathrm{x} 4)^{\mathrm{a}}$ & $\mathrm{THF}$ & $-78^{\circ} \mathrm{C}$ & Overnight & $3 \%$ \\
& & & & & \\
\hline
\end{tabular}




\begin{tabular}{|c|c|c|c|c|c|}
\hline $\mathrm{BF}_{3} \mathrm{OEt}_{2}$ & $0.4 / \mathrm{h}(\mathrm{x} 3)$ & $\mathrm{THF}$ & $-40{ }^{\circ} \mathrm{C}$ & $6 \mathrm{~h}$ & C.M. \\
\hline $\mathrm{BF}_{3} \mathrm{OEt}_{2}$ & $0.4 / \mathrm{h}(\mathrm{x} 4)$ & $\mathrm{THF}$ & $0{ }^{\circ} \mathrm{C}$ & Overnight & C.M \\
\hline TMSOTf & $0.17 / \mathrm{h}(\mathrm{x} 3)$ & $\mathrm{THF}$ & $-78^{\circ} \mathrm{C}$ & $6 \mathrm{~h}$ & $2 \%$ \\
\hline TMSOTf & $0.17 / \mathrm{h}(\mathrm{x} 3)$ & $\mathrm{THF}$ & $-40^{\circ} \mathrm{C}$ & $9 \mathrm{~h}$ & C.M. \\
\hline TMSOTf & $0.17 / \mathrm{h}(\mathrm{x} 3)$ & $\mathrm{THF}$ & $0{ }^{\circ} \mathrm{C}$ & $6 \mathrm{~h}$ & C.M. \\
\hline TMSOTf & $0.17 / \mathrm{h}(\mathrm{x} 3)$ & $\mathrm{THF}$ & $-78^{\circ} \mathrm{C}$ & $24 \mathrm{hrs}$ & $3 \%$ \\
\hline TMSOTf & $0.17 / \mathrm{h}(\mathrm{x} 3)$ & $\mathrm{THF}$ & $-78^{\circ} \mathrm{C} \rightarrow$ & $30+\mathrm{hrs}$ & C.M. \\
\hline & & & R.T. & & \\
\hline
\end{tabular}

${ }^{a}$ This notation implies that 0.4 equivalents of promotor was added every hour for 4 hours.

Before abandoning TCAs as a viable system and returning to glycosyl sulfoxides, we considered Nguyen's unusual palladium (II) catalyst, $\mathrm{Pd}\left(\mathrm{CH}_{3} \mathrm{CN}\right)_{4}\left(\mathrm{BF}_{4}\right)_{2}$, as a promoter. ${ }^{17}$ Nguyen used it as a promoter for the formation of $\beta$-glycosides through a proposed modified anchiomeric effect where the Pd chelates to a $\mathrm{C} 2$ ether as well as the nitrogen of the TCA, keeping the TCA localized to the bottom face of the oxocarbenium, forcing $\beta$-attack. In the case of mannose or rhamnose where the $\mathrm{C}-2$ ether is axial, this chelation is impossible, and an oxocarbenium intermediate followed by anomeric-effect-driven $\alpha$-glycosylation was observed (Figure 2). This meant that this chemistry was incapable of providing $\alpha$-anomers in the presence of an equatorial 
substituent at $\mathrm{C} 2$; however, we could find no examples where galactose was evaluated, nor any examples with a C-2 azide. As the azide should not complex to the Pd in the same fashion as the etheric oxygen, we believed that we would pass through an oxocarbenium instead, and the anomeric effect would preferentially drive the formation of the desired $\alpha$-product. Some reaction screening provided a new set of conditions that reliably formed $\mathbf{8}$ from $\mathbf{7}$ using the Nguyen glycosylation in up to $38 \%$ yield; importantly the starting materials can be recovered from the reaction mixture allowing for resubmission to conditions (longer reaction times started leading to product decomposition; yield based on recovered starting material is far higher; $>90 \%$, making this cost effective). The reaction was conducted by four different chemists (undergraduate, graduate, and postdoctoral) with just the written protocol, with the obtained yields being consistent. This result remains far from ideal and reaction optimization and the search for alternatives to $\mathrm{Pd}^{2+}$ salts is currently underway in the group, but this was certainly the most robust of the dozens of conditions we screened to access this material. 


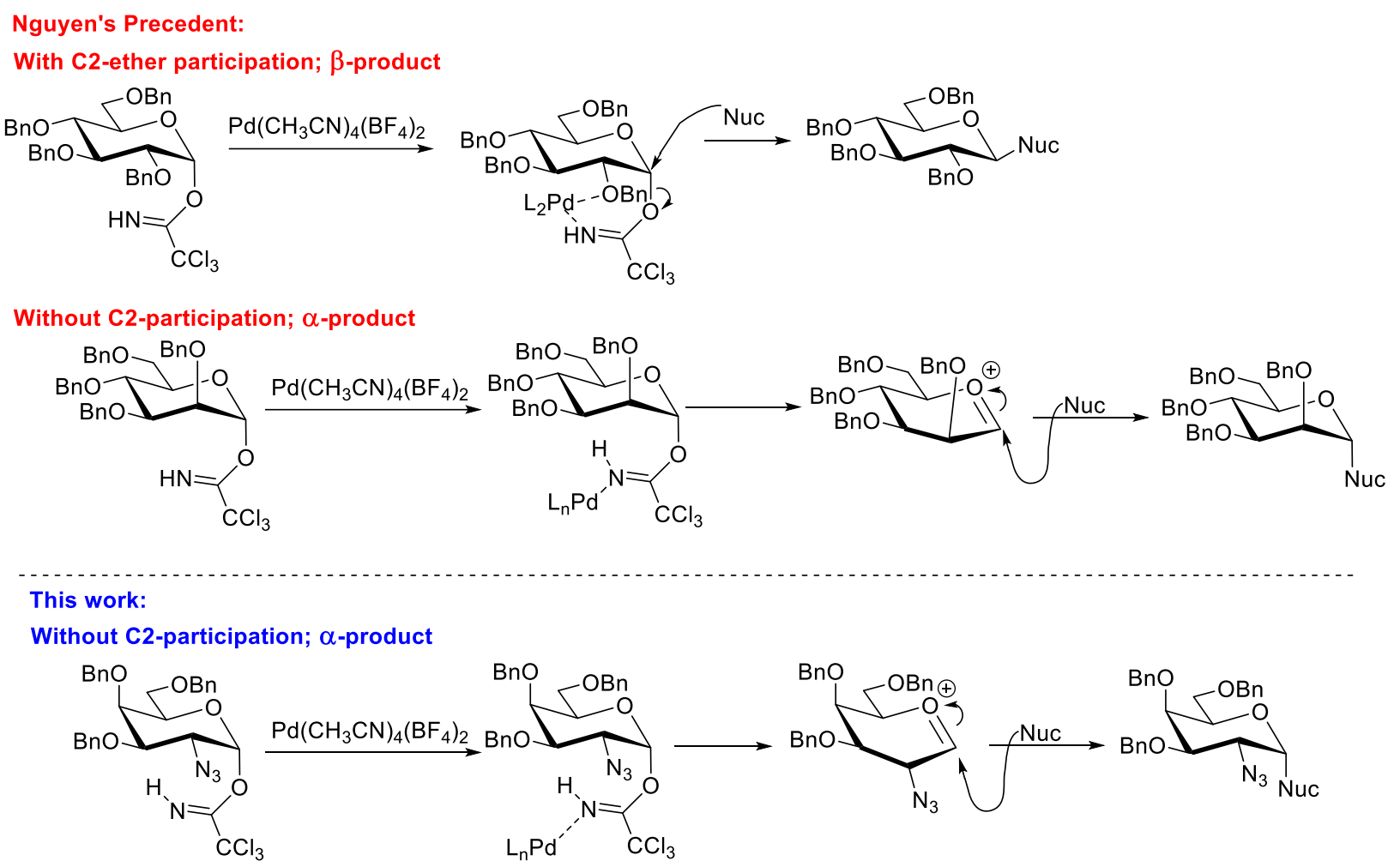

Figure 3. Proposed mechanisms of the Nguyen glycosylation in the presence or absence of a cisC-2 ether. Proposed mechanism in the presence of a cis $\mathrm{C}-2$ azide.

The final step before global deprotection is a one pot reduction and acetylation to form the NHAc functionality at C-2. Standard reducing conditions afforded $\mathbf{9}$ in high yield, and ready for incorporation into glycopeptides. Our design-of-experiment study on the Nguyen glycosylation and screening of alternate metal catalysts will be reported on in due course; samples of the Fmocprotected Tn antigen are available for collaboration or at cost. 


\section{Conclusion:}

This is the first readily scalable total synthesis of a suitably protected Tn antigen for SPPS, with a lower step-count than any other report in the literature and incorporating a robust and reproducible Nguyen glycosylation as the key step. The overall yield for the process is $7 \%$ from galactose, with only two chromatography steps, and the process can be conducted on scale in under two weeks by a practitioner skilled in the art... Or by a skilled undergraduate student while carrying out a full course-load in about 6 weeks. The intermediates are, for the most part, bench stable making this a very simple way to access this extremely important building block for glycopeptide chemistry.

CREDIT: Conceptualization, JFT; Funding acquisition JFT; Investigation, SP, JC, MRR; Methodology, SP, MRR; Project administration, JFT; Supervision, JFT; Writing original draft, SP, MRR; Writing - review and editing, SP, MRR, JFT.

\section{Acknowledgements:}

The authors would like to thank Dr. John Hayward, Iraj Sadraei, and Dina Dilinaer of the Trant Research lab for attempting the glycosylation reaction, the Windsor Cancer Centre Foundation Seeds 4 Hope program (2018-01 to JFT); the Natural Sciences and Engineering Research Council of Canada Discovery Grants Program (NSERC, 2018-06338 to JFT) the Canadian Foundation for Innovation and Ontario Research Fund (37425); the NSERC Undergraduate Student Research Award (USRA-2017 to SP); the Ontario Early Researcher Award

Program for funding this research; and MITACS Globalink for supporting FACV's research 
sabbatical with the group. Finally, JFT, MRR, and SP would like to acknowledge the Chiaramonte family for sharing J. Chiaramonte with us for too short a time, we share their grief, and miss his participation in our lives every day.

1. Sadraei, S. I.; Reynolds, M.; Trant, J. F., The synthesis and biological characterization of acetal-free mimics of the tumour-associated carbohydrate antigens. Adv. Carbohydr. Chem. Biochem. 2017, 74, 137237. DOI: http://doi.org/10.1016/bs.accb.2017.10.003

2. American Cancer Society Cancer Facts \& Figures; American Cancer Society: Atlanta, 2020. URL: http://www.cancer.org/content/dam/cancer-org/research/cancer-facts-and-statistics/annual-cancerfacts-and-figures/2020/cancer-facts-and-figures-2020.pdf

3. Siegel, R. L.; Miller, K. D.; Jemal, A., Cancer statistics, 2020. Ca-Cancer J. Clin. 2020, 70 (1), 7-30. DOI: http://doi.org/10.3322/caac.21590

4. Arteaga, C. L.; Sliwkowski, M. X.; Osborne, C. K.; Perez, E. A.; Puglisi, F.; Gianni, L., Treatment of HER2-positive breast cancer: Current status and future perspectives. Nat. Rev. Clin. Oncol. 2012, 9 (1), 16+. DOI: http://dx.doi.org/10.1038/nrclinonc.2011.177

5. Schumacher, T. N.; Schreiber, R. D., Neoantigens in cancer immunotherapy. Science 2015, 348 (6230), 69-74. DOI: http://doi.org/10.1126/science.aaa4971

6. Maia, M. C.; Hansen, A. R., A comprehensive review of immunotherapies in prostate cancer. Crit. Rev. Oncol. Hematol. 2017, 113, 292-303. DOI: http://doi.org/10.1016/j.critrevonc.2017.02.026

7. (a) Tu, M. M.; Rahim, M. M. A.; Sayed, C.; Mahmoud, A. B.; Makrigiannis, A. P., Immunosurveillance and immunoediting of breast cancer via class I MHC receptors. Cancer Immunol. Res. 2017. DOI: http://doi.org/10.1158/2326-6066.cir-17-0056 ; (b) Corthay, A., Does the immune system naturally protect against cancer? Front. Immunol. 2014, 5 (197). DOI: http://doi.org/10.3389/fimmu.2014.00197

8. (a) Sultan, H.; Fesenkova, V. I.; Addis, D.; Fan, A. E.; Kumai, T.; Wu, J.; Salazar, A. M.; Celis, E., Designing therapeutic cancer vaccines by mimicking viral infections. Cancer Immunol. Immunother. 2017, 66 (2), 203-213. DOI: http://dx.doi.org/10.1007/s00262-016-1834-5 ; (b) Hu, Z.; Ott, P. A.; Wu, C. J., Towards personalized, tumour-specific, therapeutic vaccines for cancer. Nat. Rev. Immunol. 2017, 18, 168. DOI: http://doi.org/10.1038/nri.2017.131

9. Springer, G. F., T and Tn, general carcinoma autoantigens. Science 1984, 224, 1198-1206. DOI: http://doi.org/10.1126/science.6729450

10. Kieber-Emmons, T.; Monzavi-Karbassi, B.; Hutchins, L. F.; Pennisi, A.; Makhoul, I., Harnessing benefit from targeting tumor associated carbohydrate antigens. Hum. Vaccin. Immunother. 2017, 13 (2), 323-331. DOI: http://doi.org/10.1080/21645515.2017.1264789

11. (a) Slovin, S. F.; Keding, S. J.; Ragupathi, G., Carbohydrate vaccines as immunotherapy for cancer. Immunol. Cell Biol. 2005, 83 (4), 418-428. DOI: http://doi.org/10.1111/j.1440-1711.2005.01350.x ; (b) Feng, D.; Shaikh, A. S.; Wang, F., Recent advance in tumor-associated carbohydrate antigens (TACAs)based antitumor vaccines. ACS Chem. Biol. 2016, 11 (4), 850-863. DOI: http://doi.org/10.1021/acschembio.6b00084 ; (c) Glaffig, M.; Palitzsch, B.; Hartmann, S.; Schüll, C.; Nuhn, L.; Gerlitzki, B.; Schmitt, E.; Frey, H.; Kunz, H., A fully synthetic glycopeptide antitumor vaccine based on multiple antigen presentation on a hyperbranched polymer. Chem. - Eur. J. 2014, 20 (15), 4232-4236. DOI: http://dx.doi.org/10.1002/chem.201400256 ; (d) Wilson, R. M.; Danishefsky, S. J., A vision for vaccines 
built from fully synthetic tumor-associated antigens: From the laboratory to the clinic. J. Am. Chem. Soc. 2013, 135 (39), 14462-14472. DOI: http://dx.doi.org/10.1021/ja405932r

12. Arsequell, G.; Valencia, G., O-glycosyl $\alpha$-amino acids as building blocks for glycopeptide synthesis. Tetrahedron: Asymmetry 1997, 8 (17), 2839-2876. DOI: http://doi.org/10.1016/S0957-4166(97)00326-1

13. (a) Chen, X.-T.; Sames, D.; Danishefsky, S. J., Exploration of modalities in building $\alpha$-O-linked systems through glycal assembly: A total synthesis of the mucin-related F1 $\alpha$ antigen. J. Am. Chem. Soc. 1998, 120 (31), 7760-7769. DOI: http://doi.org/10.1021/ja980724z ; (b) Kuduk, S. D.; Schwarz, J. B.; Chen, X.-T.; Glunz, P. W.; Sames, D.; Ragupathi, G.; Livingston, P. O.; Danishefsky, S. J., Synthetic and immunological studies on clustered modes of mucin-related Tn and TF $O$-linked antigens: The preparation of a glycopeptide-based vaccine for clinical trials against prostate cancer. J. Am. Chem. Soc. 1998, 120 (48), 12474-12485. DOI: http://dx.doi.org/10.1021/ja9825128 ; (c) Liebe, B.; Kunz, H., Synthesis of sialyl-Tn antigen. Regioselective sialylation of a galactosamine threonine conjugate unblocked in the carbohydrate portion. Tetrahedron Lett. 1994, 35 (47), 8777-8778. DOI: http://dx.doi.org/10.1016/S00404039(00)78495-4 ; (d) Reipen, T.; Kunz, H., Synthesis of peptide and glycopeptide partial structures of the homophilic recognition domain of epithelial cadherin. Synthesis 2003, 2003 (16), 2487-2502. DOI: http://doi.org/10.1055/s-2003-42429 ; (e) Miermont, A.; Barnhill, H.; Strable, E.; Lu, X.; Wall, K. A.; Wang, Q.; Finn, M. G.; Huang, X., Cowpea mosaic virus capsid: A promising carrier for the development of carbohydrate based antitumor vaccines. Chem. - Eur. J. 2008, 14 (16), 4939-4947. DOI: http://doi.org/10.1002/chem.200800203

14. This molecule is stable in the freezer under argon, but rapidly decomposes under ambient conditions and should not be stored on the bench overnight or longer.

15. Lemieux, R. U.; Ratcliffe, R. M., The azidonitration of tri-O-acetyl-D-galactal. Can. J. Chem. 1979, 57 (10), 1244-1251. DOI: http://doi.org/10.1139/v79-203

16. (a) Zhu, X.; Schmidt, R. R., Glycoside Synthesis from 1-Oxygen-Substituted Glycosyl Imidates. In Handbook of chemical glycosylation, Demchenko, A. V., Ed. Wiley: Weinheim, 2008; pp 143-184. DOI: http://doi.org/10.1002/9783527621644.ch3a ; (b) Schmidt, R. R.; Zhu, X., Glycosyl Trichloroacetimidates. In Glycoscience, 2nd ed.; Fraser-Reid, B.; Tatsuta, K.; Thiem, J., Eds. Springer-Verlag: Berlin, 2008; Vol. 1, pp 452-524. DOI: http://doi.org/10-1007/978-3-540-30429-6 11

17. (a) Yang, J.; Cooper-Vanosdell, C.; Mensah, E. A.; Nguyen, H. M., Cationic palladium(II)-catalyzed stereoselective glycosylation with glycosyl trichloroacetimidates. J. Org. Chem. 2008, 73 (3), 794-800. DOI: http://doi.org/10.1021/j0702436p ; (b) McKay, M. J.; Naab, B. D.; Mercer, G. J.; Nguyen, H. M., Selective formation of $\beta$-O-aryl glycosides in the absence of the $C(2)$-ester neighboring group. J. Org. Chem. 2009, 74 (13), 4705-4711. DOI: http://doi.org/10.1021/j09002807 ; (c) Mensah, E. A.; Azzarelli, J. M.; Nguyen, H. M., Palladium-controlled $\beta$-selective glycosylation in the absence of the $\mathrm{C}(2)$-ester participatory group. J. Org. Chem. 2009, 74 (4), 1650-1657. DOI: http://doi.org/10.1021/jo802468p 